\title{
Organizational and economic mechanisms for designing the development of the digital economy in developing countries
}

\author{
Saule Rakhimova ${ }^{1, *}$, Lyudmila Goncharenko ${ }^{1}$, Sergey Sybachin ${ }^{1}$, Kymbat Kunanbayeva ${ }^{2}$ \\ and Alina Fatkullina ${ }^{3,4}$ \\ ${ }^{1}$ Russian University of Economics named after Plekhanov, 36, Stremyanny per., 117997, Moscow, \\ Russia \\ ${ }^{2}$ Financial University under the Government of the Russian Federation, 49, Leningradsky Prospekt, \\ 125993, Moscow, Russia \\ ${ }^{3}$ Moscow State University of Civil Engineering, 26, Yaroslavskoye Shosse, 129337, Moscow, Russia \\ ${ }^{4}$ Moscow architectural institute, 11/4, Rozhdestvenka Street, 107031, Moscow, Russia
}

\begin{abstract}
The present article was prepared as part of the government contract as requested by the Ministry of Science and Higher Education of the Russian Federation on the subject formulated as «Structural changes in economy and society as a result of achieving the target indicators of National projects, which provide opportunities to organize new areas of social and economic activity, including commercial, both in Russia and abroad» (project No. FSSW-2020-0010).
\end{abstract}

\section{Introduction}

Over the past decades, the world has been rapidly moving towards a radically new type of economy, where digital technologies are becoming the main tool for its development and increasing competitiveness.

Digital transformation is a global and global trend that affects both developed and developing countries of the world, and digital technologies are increasing the trends of importance in accelerating the development of the economic systems of most countries.

Currently, in many countries of the world, digitalization has become one of the main priorities of strategic development along with innovation policy. For example, the Republic of Kazakhstan is implementing the state program "Digital Kazakhstan", where the main goal is to improve the quality of life of the population through the use of digital technologies, to accelerate the pace of economic development, to create conditions that allow the economy of Kazakhstan to move to a fundamentally new trajectory of development, which should ensure the creation of a digital economy of the future. In the Russian Federation, within the framework of National projects, the "Digital economy" project is being implemented. Its main goals are: to increase domestic expenditures for the development of the digital economy; to create a stable and secure information and telecommunications infrastructure for high-speed transmission, processing, and storage of

* Corresponding author: angela-1309.m@yandex.ru 
large amounts of data, accessible to all households; to use primarily domestic software by government agencies, local governments and organizations.

According to the forecasts of the world's leading experts, almost more than a quarter of the world economy will be digital by 2025 . All spheres and sectors of the economy will be subject to digitalization: the public sector, the sector of large industrial enterprises, the sector of small and medium-sized businesses, and the social sphere. In other words, interaction schemes in digitalization will work: "B2B" (business - business); "B2C" (business - consumer); "C2C" (consumer - consumer); G2B (government - business); G2C (government - consumer). Considering this aspect, each country in the developed strategic plans should strive to provide for the development of those sectors of the economy that play the greatest role in the digitalization of production and economic processes.

\section{Materials and Methods}

A digitalization of the economy for developing countries is a relatively new and promising direction. In the science of these countries, research has been conducted only to a small extent on the conceptual apparatus of digitalization of economic processes, the impact of digitalization processes on economic growth, the level of innovation and competitiveness of the economy, and social processes. The existing potential for predicting the prospects of digital development has also been studied to a small extent. The process of building a digital economy, relative to global digitalization processes - is a new stage in the development of developing countries based on the principles of "Industry 4.0 " trends. It is important to build the main organizational and economic mechanisms for the development of digitalization at the macro and micro levels.

According to generally accepted encyclopedic data, the digital economy is the process of functioning of an economic system based on the complex application of computer technology, software, digital communications, and network communications [1].

The digital economy covers all subsystems of government activity, including:

- production of goods and services;

- distribution of goods and services;

- consumption of goods and services;

- cash flow (digital currency);

- social processes in society.

The conceptual model of the digital economy is presented in fig. 1 . 


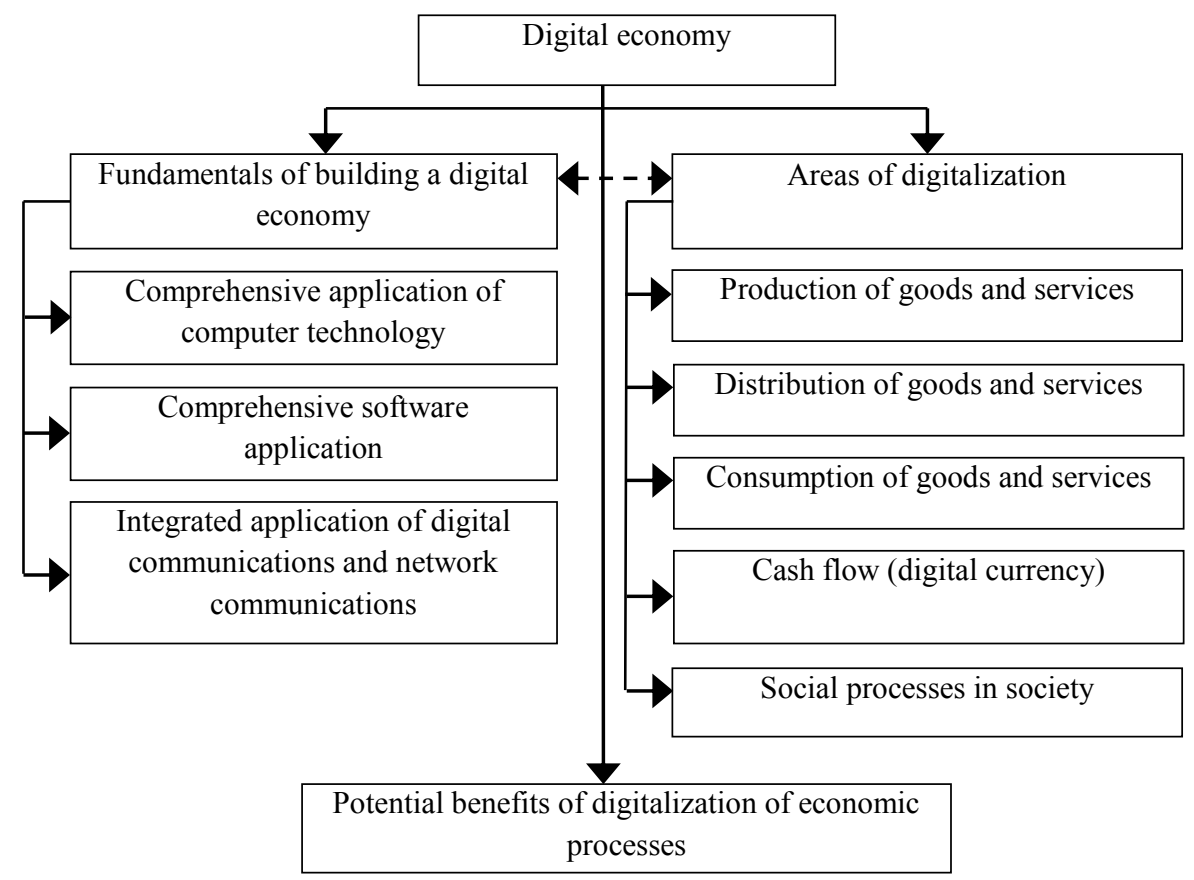

Fig. 1. Conceptual model of the digital economy (Compiled by the authors from [1]).

There is a different range of scientific approaches to understanding the essence of the digital economy. Thus, the digital economy is considered in the following interpretations:

- information economy;

- knowledge economy;

- innovative economy;

- e-economy;

- cybernetic economy.

Organizational and economic mechanisms for designing the development of the digital economy can be created and designed at the state (macroeconomic) level, as well as at the meso- and microeconomic levels.

Although the processes of digitalization at all economic levels can be carried out simultaneously, in modern theory, the first stage of digitalization should relate to the macroeconomic level. In this case, from an organizational point of view, the algorithm for designing and developing the digital economy will take the form in accordance with figure 2 . 


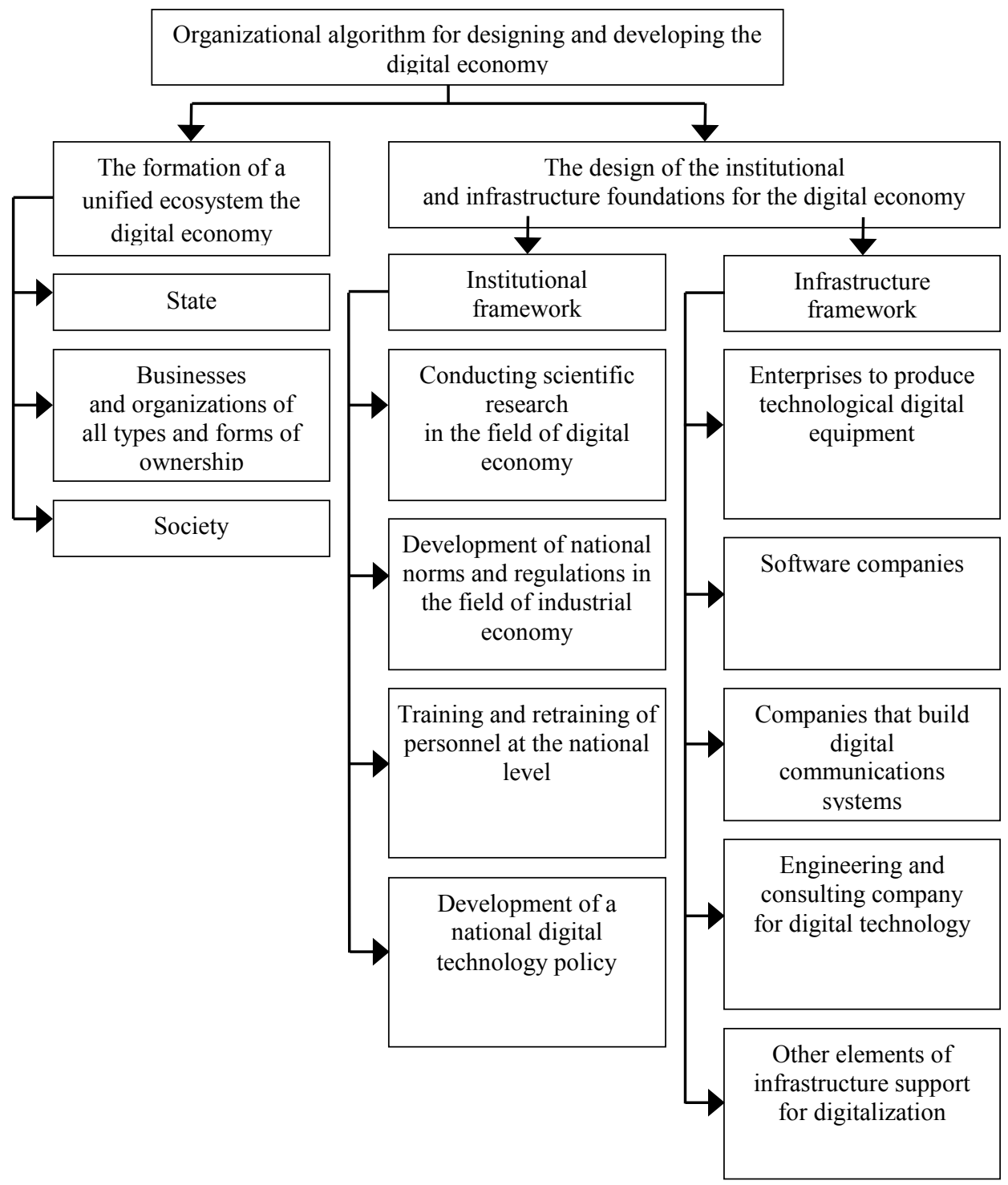

Fig. 2. Organizational algorithm for designing and developing the digital economy (Compiled by the authors).

Special importance in designing the organizational foundations of the digital economy should be given to the functioning of electronic industry enterprises. This aspect is relevant because computer equipment, in accordance with figure 3 , has a progressive period of 3 to 5 years, after which they require complete replacement. 


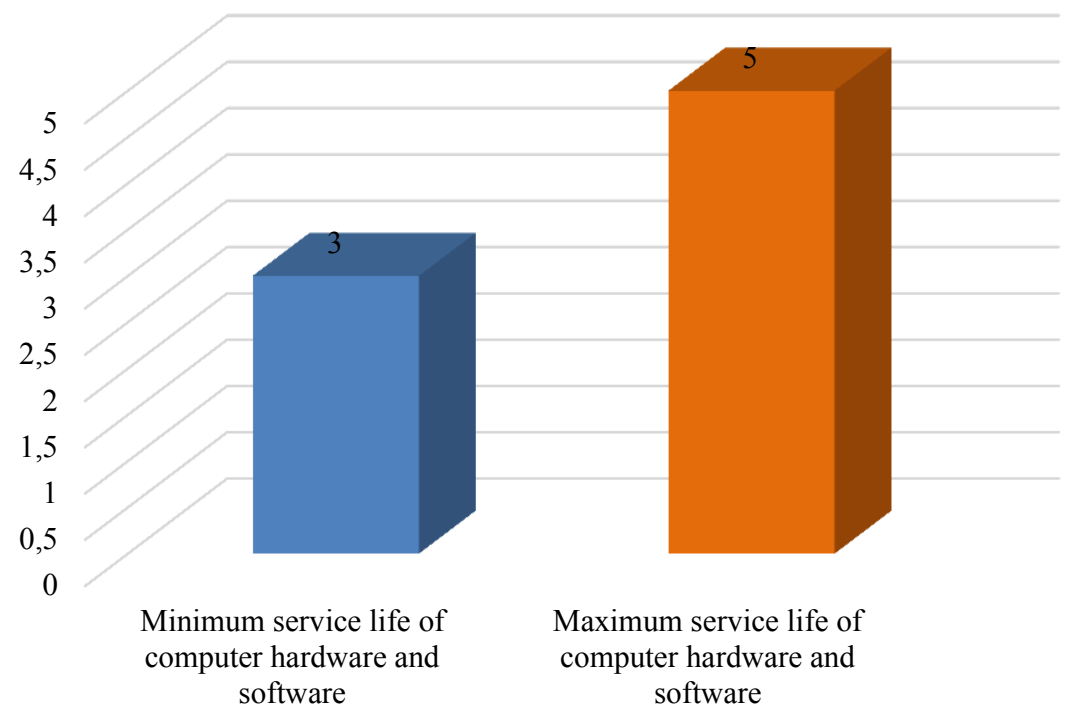

Fig. 3. Minimum and maximum service life of computer hardware and software in terms of progressiveness (Compiled by the authors from [2]).

In turn, the fact presented above forms the economic basis for building and developing the digital economy at the national level, as shown in figure 4.

Investment in capital construction of electronic industry enterprises is one of the most important investments in the construction and development of the digital economy. These investments will ensure sustainability in the medium and strategic term of the following sectors:

- state management of the economy;

- functioning of the banking sector;

- higher education sector;

- healthcare industry;

- electric power industry;

- the military-industrial complex [3]. 


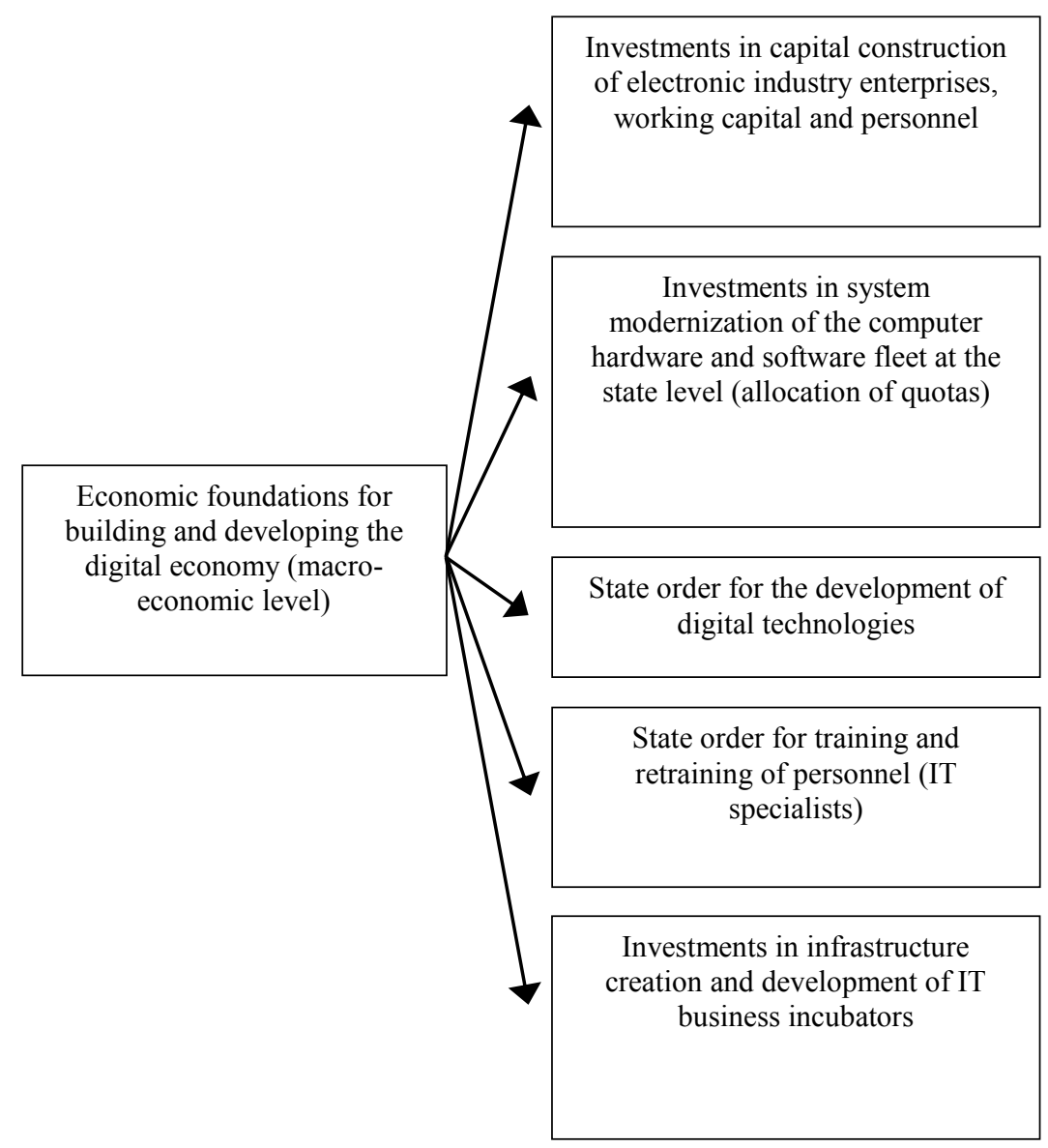

Fig. 4. Economic foundations for building and developing the digital economy (Compiled by the authors from [3]).

\section{Results}

In the process of investing in the electronic industry, the main targets are:

- main production assets;

- current assets;

- human resources.

Direct investments in the system modernization of the computer equipment and software fleet at the state level can be implemented through a system of quotas and special grants.

When intensifying the development of the electronic industry, the following measures are used as additional organizational and economic mechanisms:

- establishment of effective and efficient customs duties on electronic products imported into the country, the production of which is technologically, and organizationally, and economically possible in the country;

- abolishing the "grey" import of electronic products;

- targeted financing of fundamental and applied works on the development of production technologies, directly for electronic industry products;

- investment in incubation processes of start-up IT companies and corporations; 
- funding for the creation of point-to-point prototypes of electronic industry products [4].

When forming a state order for training and retraining of personnel (IT specialists), various variable organizational and economic mechanisms are developed, as shown in figure 5 [5].

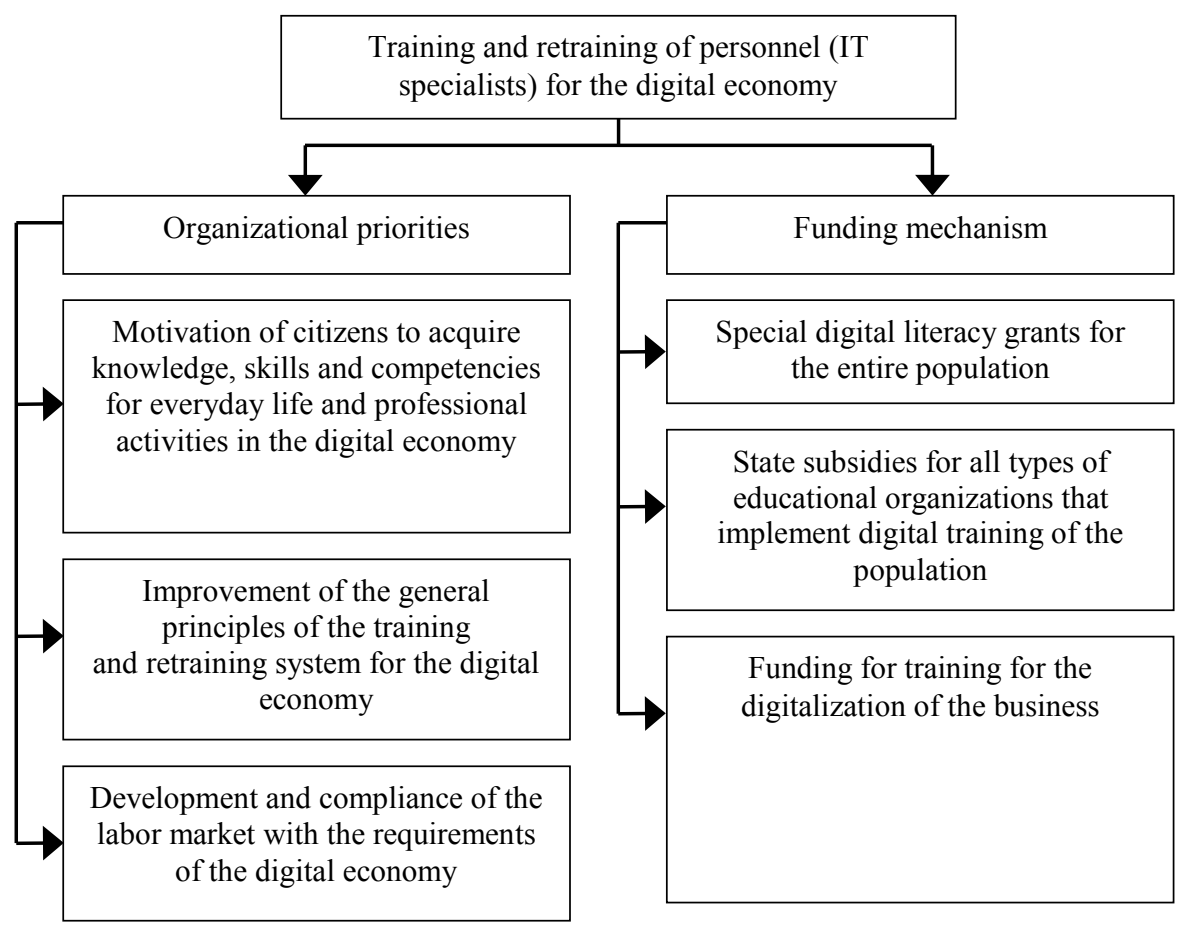

Fig. 5. Organizational and economic mechanisms when forming a state order for training and retraining of personnel (IT specialists) (Compiled by the authors from [4, 5]).

The following are direct tools for motivating citizens to acquire knowledge, skills and competencies for everyday life and professional activities in the digital economy:

- providing state certificates to individuals for digital literacy.

- providing grants for teaching digital literacy based on the principles of competitions, Olympiads.

- training and assignment of "Digital Boyscouts' Self-improvement" status».

- financing the development of new digital programs [5].

The following tools are used to finance educational organizations as part of the digital economy training framework.

- funding programs to find and develop optimal and effective models of digital universities.

- funding for research and implementation of the world's best training practices for the digital economy.

- financing the attraction of foreign specialists for training.

- creation of venture funds focused on training personnel for the digital economy [5].

At the microeconomic level, the policy of formation and development of the digital economy is developed by the top management of enterprises, firms, and companies. The main organizational and economic priorities for the formation and development of the digital economy at the microeconomic level are shown in figure 6.

The economic effect of digitalization processes at the microeconomic level can be 
defined by the expression:

$$
E b d=\frac{E p d}{I s+I h+I h r}
$$

where

$E_{b d}-$ economic benefits of digitization;

$E_{p d}$ - potential economic benefits of digitalization;

$\mathrm{I}_{\mathrm{S}}$ - investments in computer software;

$\mathrm{I}_{\mathrm{h}}$ - investments in computer hardware, other digital equipment;

$\mathrm{I}_{\mathrm{HR}}$ - investment in human resources, and training for digitalization of business processes in the enterprise.

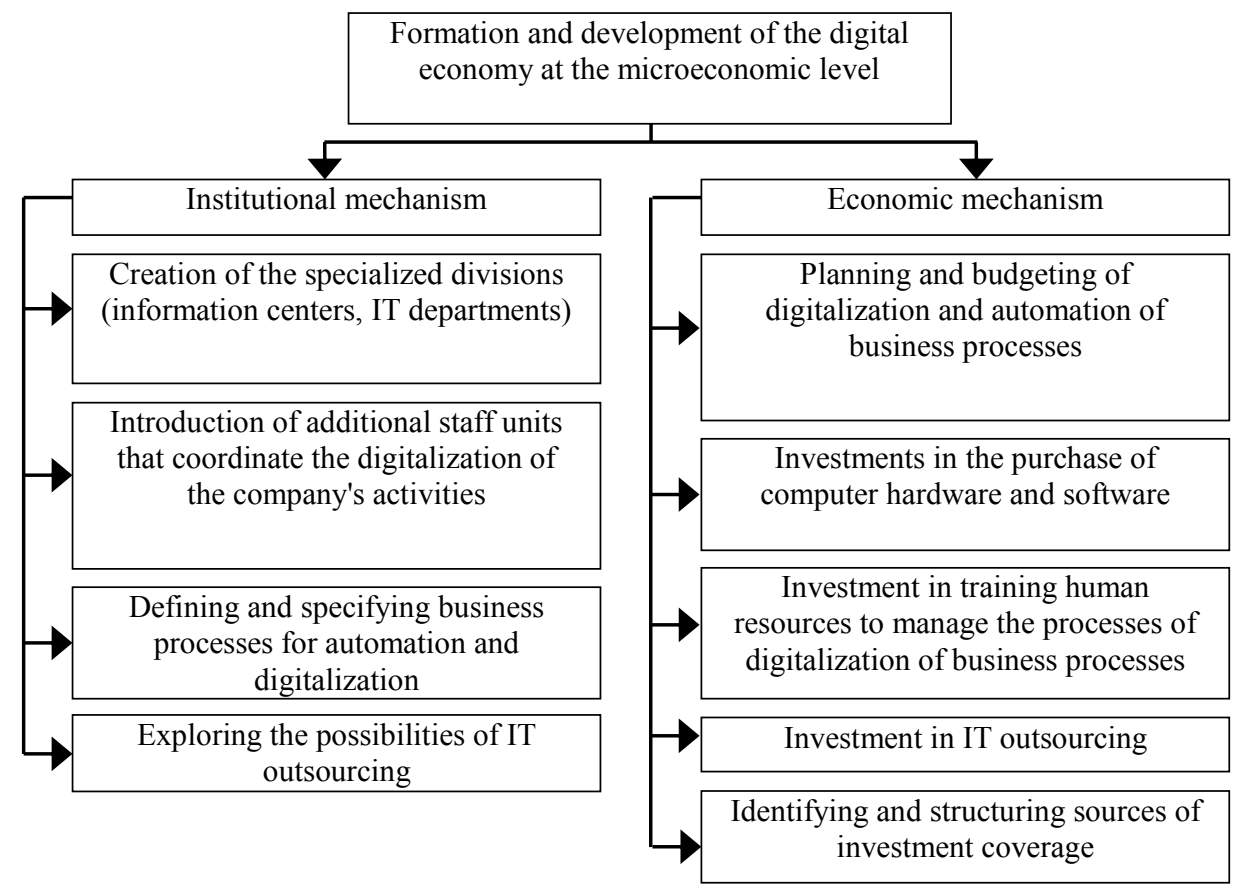

Fig. 6. Main organizational and economic priorities for the formation and development of the digital economy at the microeconomic level (Compiled by the authors).

\section{Conclusions}

Studying the organizational and economic mechanisms of designing the development of the digital economy, we can conclude that the processes of digitalization requires attention, both from the private sector of the economy and from the state. At the same time, the formation of the ecosystem of the digital economy is inherent in the state, which is endowed with tools for implementing policies at the macroeconomic level. Without the participation of microeconomics entities - enterprises, firms, companies, building a digital economy is also impossible since their digitalization processes are part of the ecosystem. At the same time, the digital economy should have a synergy of private and public capital. 


\section{References}

1. Cifrovaya ekonomika, https://ru.wikipedia.org/wiki/ a

2. M.A. Mel'nikov, N.N. Skornichenko, Ekonomika i upravlenie 9(3) (2018)

3. L. Shabalina, L. Kopteva, A. Mottaeva, E3S Web of Conferences 175, 13040 (2020) https://doi.org/10.1051/e3sconf/202017513040

4. N. Ledencov, Perspektivy razvitiya elektronnoj promyshlennosti. Vzglyad izdaleka, http://www.electronics.ru/journal/article/847

5. A.V. Bataev, A.A. Gorovoy, A.B. Mottaeva, Proceedings of the 32nd International Business Information Management Association Conference, IBIMA 2018 - Vision 2020, 102-114 (2018)

6. Y.V. Morozyuk, A.V. Sharkova, I.A. Merkulina, O.N. Vasilyeva, Journal of Environmental Management and Tourism 8.3(19), 507-515 (2017) 